\title{
Breast-feeding in Spain
}

\author{
M Lozano de la Torre ${ }^{1, *}$, J Martín-Calama ${ }^{2}$ and MT Hernandez-Aguilar ${ }^{3} \dagger$ \\ ${ }^{1}$ Marqués de Valdecilla University Hospital, Children's Department, Cantabria University, E-39008 Santander, \\ Spain: ${ }^{2}$ Obispo Polanco Hospital, Children's Department, Teruel, Spain: ${ }^{3}$ Fuente de San Luís, Public Health, Primary \\ Care Centre, Valencia, Spain
}

\begin{abstract}
Human milk is the best way to nurture the human infant. By breast-feeding their babies, mothers provide them with the best opportunities to wholly develop their potential, while protecting the infants and themselves from a whole range of diseases in the near future and in the years to come.

Even though these benefits are widely known and there is ample scientific evidence on the topic, it seems from published data that Spanish women are not breastfeeding their babies as much and for as long as they should. Less than $90 \%$ start breast-feeding, at 1 month there is already an attrition of $30 \%$, at 3 months more than half of the infants are taking artificial milk and by 6 months only 10\% continue to breast-feed their infants.

Low birth weight, Caesarean section and low study level are among the more significant factors that negatively affect breast-feeding.

There is still work to do to improve this situation. Promotion of breast-feeding among the general population, mothers and health professionals is needed.
\end{abstract}

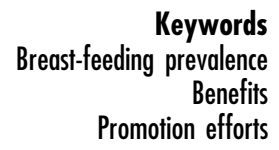

Human milk is not only the best form of nourishment for the human infant, but also (and not the least) provides the baby and her mother with incomparable biological and psychological benefits.

\section{In what aspects is buman milk beneficial for the buman infant?}

Human milk is specifically adapted to the unique digestive and metabolic characteristics of the human infant. Macroand micronutrients are supplied in the right amount. Although the exact importance of some of these nutrients is yet to be disclosed, human milk ensures the best nutrition for the normal infant in the first months of life.

Compared with artificial feeding, breast-feeding has been clearly shown to be protective against many different infections in infants. Controlled and welldesigned studies in developed countries have demonstrated that infants who are breast-fed for more than 13 weeks suffer less gastrointestinal infections, respiratory infections and urinary infections and require fewer hospital admissions ${ }^{1}$. This anti-infection protective effect has been demonstrated in our own population, in a recent multi-centre study whose conclusions were presented in the First Spanish Congress on Human Lactation, held in Valencia (Spain) in February 2000 ${ }^{2}$.

Some studies have also found that prolonged breast-

tThe authors are members of the Spanish Committee on Human Lactation, Spanish Paediatric Association. feeding along with late introduction of some complementary foods may delay or ameliorate the onset of some allergic symptoms in children with a family history of atopic disease ${ }^{3}$.

The influence of human breast-feeding on intellectual and psychological development has been, and continues to be, the subject of many debates. Intelligence as a global concept is the result of integrating several factors such as genetics, environment, emotional components, character and physical development (trophic component). The presence in human milk of several hormones, enzymes and trophic factors may positively influence infant development and probably condition better interactions with the environment and a higher ability to respond to surrounding stimuli, basically the mother ${ }^{4}$.

Consequences of nourishment during infancy are difficult to evaluate in the long run due to the influence of many other factors (genetic and environmental) that interact during childhood and in adult life. However, a few studies have found different beneficial effects of breast-feeding later in life.

Epidemiology suggests there is a relationship between early introduction of cow's milk (or derivatives) and diabetes mellitus I, even though a few years may elapse before agreement on a definitive and widely accepted conclusion on this issue ${ }^{5}$. Meanwhile, the American Academy of Pediatrics recommends breast-feeding in infants of families with a positive familial history of 
diabetes mellitus, avoiding, if possible, any product containing whole cow's milk protein in the first year of life $^{6}$.

Case-control studies suggest that non-breast-fed infants are subject to a higher risk for Hodgkin's disease ${ }^{7}$. It seems that duration of breast-feeding is inversely related to risk for this disease. However, the biological reason is yet unknown ${ }^{7}$.

A retrospective study on patients with Crohn's disease found that no breast-feeding at all was a risk factor associated with development of the disease later ${ }^{8}{ }^{8}$. However, this finding was not confirmed by other investigators 9,10 . There is still no official conclusion on this issue. Some authors suggest that the better immune tolerance found in breast-fed infants may explain the preventive effect of exclusive breast-feeding during the first months of life of the human infant on diminishing risk for late development of Crohn's disease.

\section{Is it beneficial for the mother, as well?}

Breast-feeding increases oxytocin serum levels; this reduces risk for postpartum haemorrhages and accelerates uterine involution ${ }^{11}$. It has also been found that breast-feeding mothers improve their postpartum remineralisation $^{12}$ processes, which, in turn, diminishes risk for postpartum hip fractures ${ }^{13}$. With regard to the beneficial effect of human milk on breast cancer in menopausal women, it seems that duration of breastfeeding is inversely related to breast cancer risk in premenopausal females ${ }^{14-16}$ although this has not been demonstrated in other studies ${ }^{17,18}$. A multi-centre study found lower relative risk of ovarian cancer for women who were breast-feeding their infants ${ }^{19}$.

Human breast-feeding also has social and economic benefits for the whole family. Breast-feeding helps reduce the cost of the public health system, by reducing infant morbidity $^{20}$ and absenteeism in the mother. It is also cheaper for mothers, who reduce by a considerable amount the cost derived from artificial feeding ${ }^{21}$.

Widespread abandonment of breast-feeding, which has characterised the 20th century, has been considered the most significant change in human behaviour registered in history ${ }^{22}$. It has been compared with energy crises, as an important waste of high-value natural resources, most important in developing countries. Others have described the introduction of artificial milk as the world's largest experiment without controls ${ }^{23}$.

International health institutions and nutrition organisations, aware of the importance of human milk for the infant, child and maternal health, have considered breastfeeding promotion as one of their priorities. The World Health Organization (WHO) declared as an objective that, by the year 2000, all women should breast-feed their infants and all infants should be exclusively breast-fed during the first six months of life $\mathrm{e}^{24}$.

\section{Prevalence of breast-feeding in Spain}

In Spain, the analysis of published results of prevalence surveys conducted during the last few years (Fig. 1) and

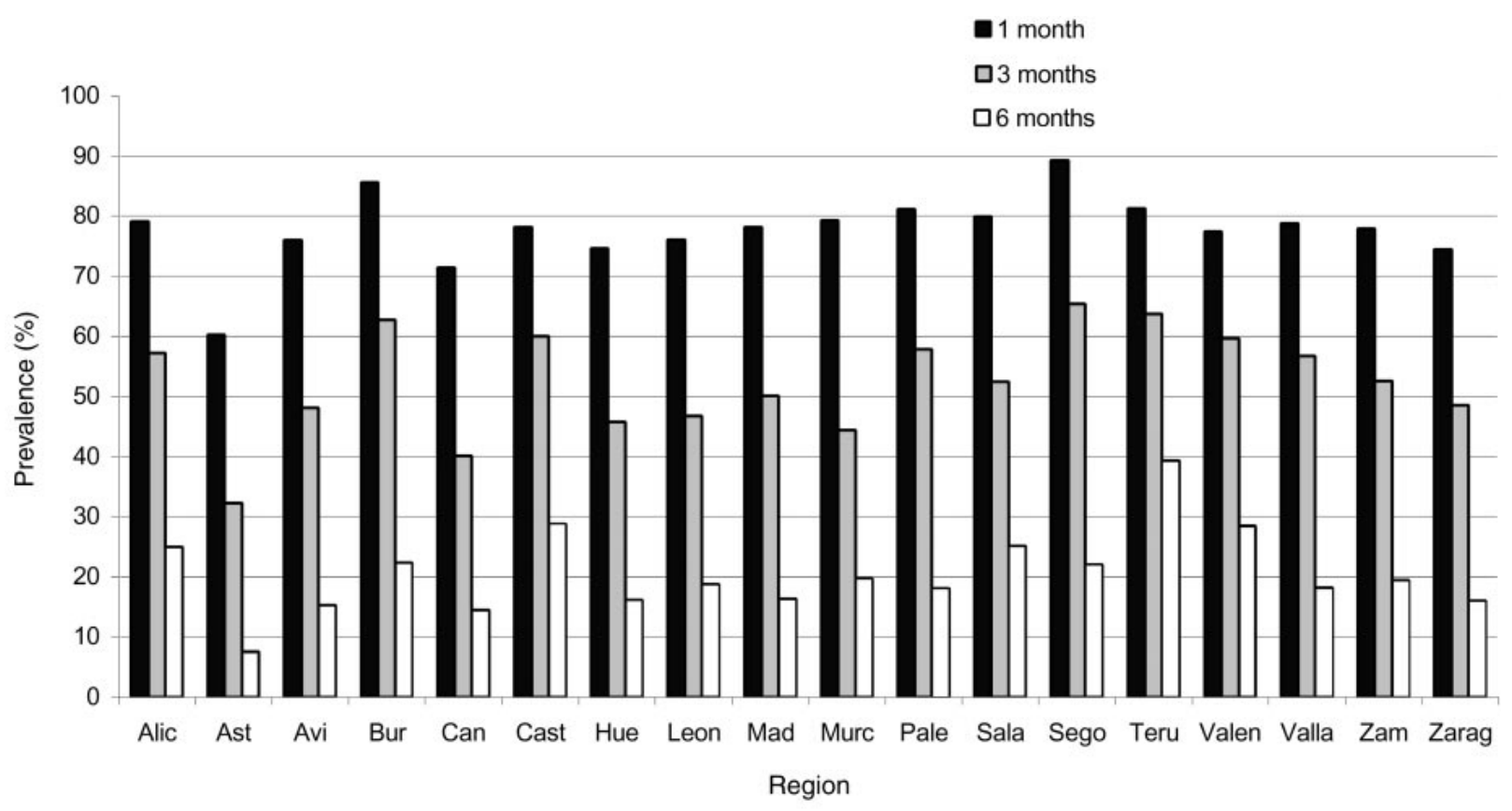

Fig. 1 Prevalence of breast-feeding mothers at 1, 3 and 6 months after birth in selected Spanish regions (source: Martin Calama et al. ${ }^{25}$ ). Alic - Alicante; Ast - Asturias; Avi - Avila; Bur - Burgos; Can - Cantabria; Cast - Castellón; Hue - Huesca; Leon - Leon; Mad - Madrid; Murc - Murcia; Pale - Palencia; Sala - Salamanca; Sego - Segovia; Teru - Teruel; Valen - Valencia; Valla - Valladolid; Zam - Zamora; Zarag - Zaragoza 


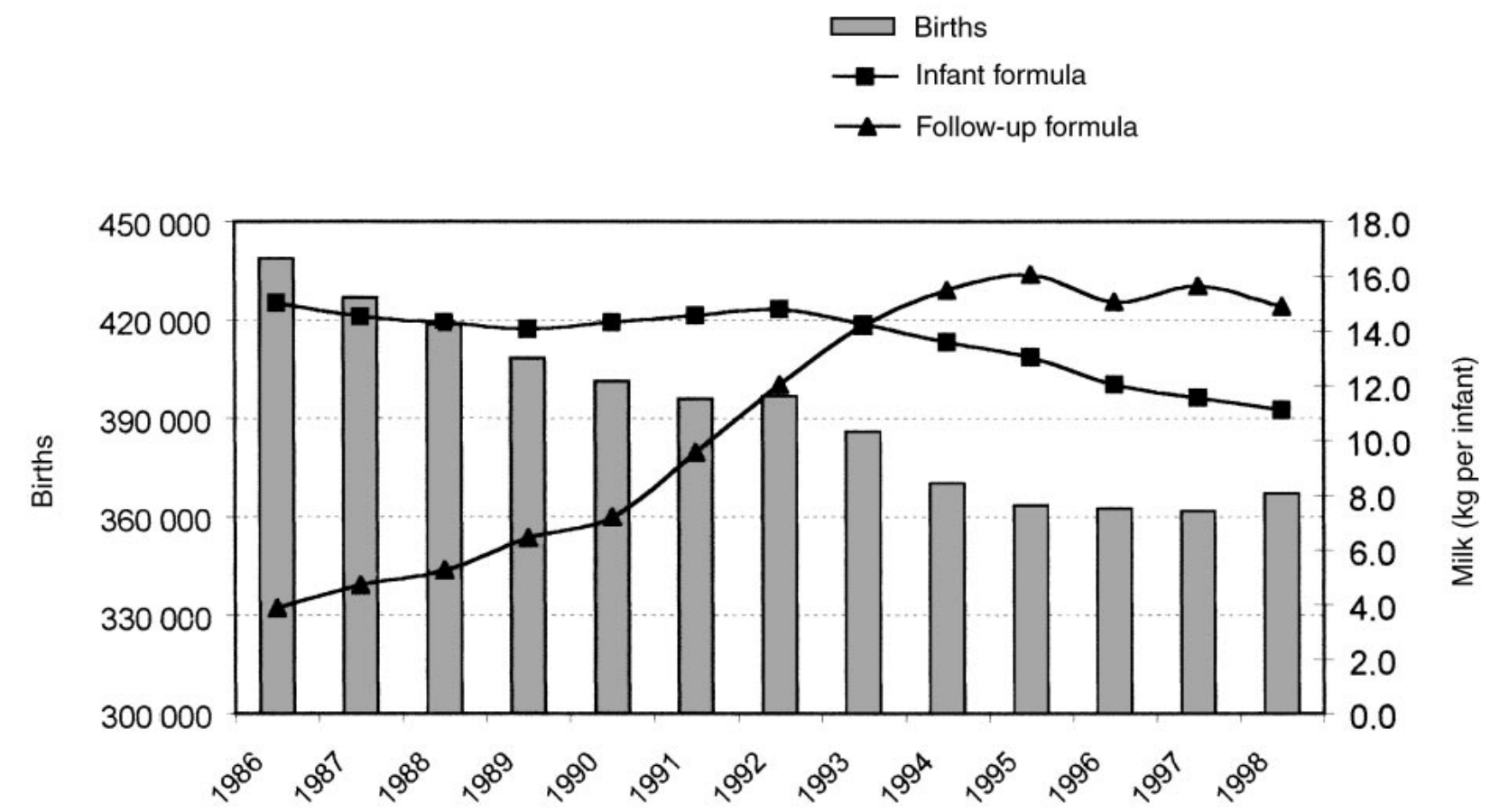

Fig. 2 Infant and follow-up formula milk sales in Spain $\left(\mathrm{kg} \mathrm{infant}^{-1}\right.$ ) from 1986 to 1998 (source: Martin Calama et al. ${ }^{25}$ )

of reports of artificial milk sales (Fig. 2) shows that there is a moderate trend towards an increasing prevalence of breast-feeding. This is not the same in all provinces of Spain $^{25,26}$. The Spanish National Health Survey (19951997) reflected an increase in the prevalence of breastfeeding at 6 weeks, and 3 and 6 months ${ }^{27}$. However, there is still an important proportion of early abandonment. Even if there are many mothers who wish to breast-feed their infants, and start doing it, they fail to continue breast-feeding in the first weeks. Results from the National Survey on Breast-feeding, conducted on random samples of infants in several Spanish regions in 1997, showed that among infants less than 29 days old, 64\% were exclusively breast-fed. This percentage was reduced to $32.5 \%$ among 3-month-old infants and shrank to $10 \%$ among 6-monthold infants. More than half (66.8\%) of the 3-month-old infants were already receiving formula milk (15\% of those with breast milk). After the eighth month less than 5\% received breast milk.

Birth weight significantly influenced the probability of not being breast-fed. Low-birth-weight and premature infants were at high risk of not being breast-fed; the lower the birth weight or gestational age, the lower the probability of being breast-fed. Children born by Caesarean section or having neonatal problems were at a higher risk of not being breast-fed. The mother's level of education also had an influence; lower education level increased by 1.5 the probability of not being breast-fed. We did not find significant differences for having siblings, gender of the infant, work status of the mother, maternal age or maternity leave, regarding the risk for infants not being breast-fed.

\section{Discussion}

Most frequently alleged for early breast-feeding abandonment is 'hypogalactia'. This is described by mothers as lack of milk, no sensation of full breasts and a restless infant, who does not calm with breast-feeding. On many occasions this is accompanied by perceived slow weight gain, and in the end the mother or father offers the baby some formula milk with a teat, as a pacifier. All this, sooner or later, leads to the abandonment of breast-feeding.

Nowadays it is widely known that most of such hypogalactia is due to technique errors (wrong hospital routines, incorrect breast-feeding technique, etc.). These could be avoided if health personnel, in charge of maternal and child areas, were familiar with breastfeeding techniques, breast-feeding problems, frequently asked questions, how and what to do ${ }^{28}$.

It is not only necessary to increase knowledge and abilities, but it is even more important to overcome barriers to breast-feeding by changing attitudes. Most health professionals related to maternal and child health care agree that breast-milk is the best food for the human infant. However, daily practice is not exactly the same, and in many cases wrong practices lead to disappointment and abandonment. Several studies have demonstrated the negative influence of adopting a neutral 
attitude at some critical moment, or not knowing how to help a breast-feeding mother with a problem ${ }^{29}$. Thus, the first important need is to ensure that health professionals are properly trained to have appropriate knowledge and the skills required ${ }^{30}$. Some authors found differences between mothers who abandon and those who do not basically rely on the support received from health personnel, rather than the existence of problems or difficulties ${ }^{31}$. All health personnel should be properly informed on the physiology and technique of breastfeeding; should be familiar with possible problems and adequate solutions to them; and should be ready to stimulate and support breast-feeding mothers ${ }^{32}$. Changing attitudes of health personnel towards breast-feeding is essential and should be a priority, even before addressing the activities of public health awareness and health education directed towards pregnant mothers or the general public.

For effective promotion of breast-feeding, identification of key moments to intervene and the professionals involved at every stage is of utmost importance ${ }^{29}$.

Prenatal interventions should be aimed at providing future parents with the required information on nutritional, immunological, psychological, economic and ecological benefits of breast-feeding, both for mother and infant. Future mothers should learn about the physiology of lactation and become familiar with the technique. Breast-feeding can be considered as a technique to learn. Some authors have found that this type of learning is more useful for first-time mothers ${ }^{33}$. Obstetricians, midwives and paediatricians are the personnel responsible for these tasks.

The immediate postpartum period is critical in the establishment of breast-feeding and its success. In 1989, WHO and the United Nations Children's Fund (UNICEF) published 'Ten Steps for Successful Breastfeeding'. This initiative was aimed at protection of the rights of breastfeeding mothers and their infants by establishing protective policies in hospitals, maternity clinics and all places where children are born ${ }^{28}$. Step No. 4 states that mothers should be helped to put their infants to the breast in the first half hour after labour. Several studies have found that this early suckling from the breast has an enormous influence on the duration of breast-feeding ${ }^{34-36}$. Step No. 8 defends that breast-feeding should be on demand. Mothers should be advised to put their infants to the breast as soon as they show signs of hunger or whenever they show signs of wanting the breast. Demand breastfeeding has several advantages: less weight loss after birth, lower levels of serum bilirubin, helps the mother prevent mammary engorgement and helps establishing lactation. Breast-feeding on demand is related to prolonged breast-feeding ${ }^{33}$.

After leaving the clinic, primary health-care professionals (paediatricians, midwives and paediatric nurses) are the ones in charge of providing support to the mother.
It is their task to be informed and to have the appropriate knowledge on the technique of breast-feeding. They should also be able to solve late problems that may appear, such as painful nipples, breast rejection, mastitis, colic and crying, interference with mother's sleep, interpretation of weight gains, the mother who works, maternal illnesses, maternal medications and breastfeeding, weaning, etc. ${ }^{37}$.

\section{Conclusions}

Health professionals are not the only ones involved in supporting the onset and duration of breast-feeding. It is the role of politicians and authorities to protect the rights of mothers and infants since breast-feeding is a social good, offering enormous advantages to society: healthier and more equilibrated citizens on the one hand, and enormous savings on health costs, formula costs, teats, pacifiers and boiling on the other. From an ecological point of view, breast-feeding contributes to generate less waste, saving the energy used in producing formula milk, and not wasting existing resources that are free.

Several governments have signed the following commitments, which should be reminded:

- the appointment of a national breast-feeding coordinator;

- the appointment of a multisectorial breast-feeding committee, where governmental, non-governmental and health organisations are represented;

- to implement the WHO code for the marketing of infant feeding products;

- to approve innovative legislation that protects breastfeeding rights for working mothers and to establish ways to implement this legislation; and

- to ensure that maternity clinics accomplish the 'Ten Steps for Successful Breastfeeding'.

\section{References}

1 Howie PW, Forsyth JS, Ogstin SA, Clark A, Florey CD. Protective effect of breastfeeding against infection. BMJ 1990; 300: 11-6.

2 Paricio JM. Lactancia materna y morbilidad infecciosa en el primer año de vida. In: I Congreso Español de Lactancia Materna. Valencia: Martin Calama edit, 1999; 61-4.

3 Saarinen UM, Kajossari M. Breastfeeding as prophylaxis against atopic disease: prospective follow up study until 17 years old. Lancet 1995; 346: 1065-9.

4 Ballabriga A, Carrascosa A. Lactancia materna. In: Ballabriga A, Carrascosa A, eds. Nutrición en la Infancia y Adolescencia. Madrid: Ergon edition, 1998; 33-78.

5 Norris JM, Beauty B, Klingensmith B, Yu Liping, Hoffman M, Chase HP, Erlich HA, Hamman RF. Lack of association between early exposure to cow's milk protein and B-cell autoimmunity. JAMA 1996; 276: 609-14.

6 American Academy of Pediatrics. Work group on cow's milk protein and diabetes mellitus. Infant feeding practices and their possible relationship to the etiology of diabetes mellitus. Pediatrics 1994; 94: 752-4. 
7 Davis MK. Review of evidence for an association between infant feeding and childhood cancer. Int. J. Cancer Suppl. 1998; 11: 29-33.

8 Koletzko S, Sherman P, Corey M, Griffiths A, Smith C. Role of infant feeding practices in development of Crohn's disease in childhoood. BMJ 1999; 298: 1617-8.

9 Gilat T, Hacohen D, Lilos P, Langman MJS. Childhood factors in ulcerative colitis and Crohn's disease. An international cooperative study. Scand. Gastroenterol. 1987; 22: 1009-24.

10 Goldman AS. The immune system of human milk: antimicrobial, antiinflamatory and immunomodilating properties. Pediatr. Infect. Dis. J. 1993; 12: 664-71.

11 Chua S, Arulkumaran S, Lim I, Salamat N, Ratman S. Influence of breastfeeding and nipple stimulation on postpartum uterine activity. Br. J. Obstet. Gynaecol. 1994; 101: $804-5$.

12 Melton LJ, Bryant SC, Wahner HW, O'Fallon WM, Malkasian GD, Judd HL, Riggs BL. Influence of breastfeeding and other reproductive factors on bone mass later in life. Osteopor. Int. 1993; 3: 76-83.

13 Cumming RG, Klineberg RJ. Breastfeeding and other reproductive factors and the risk of hip fractures in elderly woman. Int. J. Epidemiol. 1993; 22: 684-91.

14 Haring MH, Rookus MA, Van Leeuwen FE. Does breastfeeding protect against breast cancer? An epidemiological study. Ned. Tidjschr. Geneeskd. 1992; 136: 734-7.

15 United Kingdom National Case-Control Study Group. Breastfeeding and risk of breast cancer in young women. BMJ 1993; 307: 17-20.

16 Newcomb PA, Storer BE, Longnecker MP, Mittendorf R, Greenberg ER, Clapp RW, Burke KP. Lactation and a reduced risk of premenopausal breast cancer. N. Engl. J. Med. 1994; 330: 81-7.

17 Thomas DB, Noonan EA. Breast cancer and prolonged lactation. The WHO collaborative study of neoplasia and steroid contraceptives. Int. J. Epidemiol. 1993; 22: 619-26.

18 Michels B, Willett WC, Rosner BA, Manson JE, Hunter DJ, Colditz GA, Hankinson SE. Prospective assessment of breastfeeding and breast cancer incidence among 89,887 women. Lancet 1996; 347: 431-6.

19 Rosenblatt KA, Thomas DB. WHO collaborative study of neoplasia and steroid contraceptives. Int. J. Epidemiol. 1993; 22: 192-7.

20 Cohen R, Mrtek MD, Mrtek RG. Comparison of maternal absenteeism and illness rates among breast-feeding and formula-feeding women in two corporations. Am.J. Health Promotion 1995; 10: 148-52.
21 Walker M. Why aren't more mothers breastfeeding? The benefits are clear. So how do we convince mothers? Childbirth Instructor 1992; 19-24.

22 Hendricks RG. Socio-economic and psychological factors in breastfeeding motivation. Bull. Int. Ped. Assoc. 1976; 6: 3744.

23 Lawrence R. Breastfeeding. A Guide for the Medical Profession. Barcelona: Mosby edit, 1994.

24 World Health Organization's infant-feeding recommendation. Weekly Epidemiol. Record 1995; 7: 119-20.

25 Martin Calama J, Lozano MJ, Muñoz A. Comité de lactancia de la AEP: informe técnico de la lactancia materna en España. An. Esp. Pediatr. 1999; 50: 333-40.

26 Martín Calama J, Lozano de la Torre MJ. Lactancia materna. Pediatrika 1999; 1(Suppl.): 14-22.

27 Dirección General de Salud Pública. Encuesta Nacional de Salud. Madrid: Ministerio de Sanidad y Consumo, 1999.

28 Joint WHO/UNICEF Statement. Protecting, Promoting and Supporting Breast-feeding. The Special Role of Maternity Services. Geneva: WHO, 1989

29 Pechevis M. Training health professionals: general. In: Jelliffe DB, Jelliffe EFP, eds. Programmes to Promote Breastfeeding, 1st ed. Delhi: Oxford University Press, 1988.

30 Jelliffe DB, Jelliffe EFP. Programmes to Promote Breastfeeding, 1st ed. Delhi: Oxford University Press, 1988.

31 Cole JP. Breastfeeding in the Boston suburbs in relation to personal-social factors (are paediatricians thoughtlessly influencing the outcome in their postpartum care?). Clin. Pediatr. 1977; 16: 352-6.

32 Jelliffe EFP. Breastfeeding modules for integration into the curriculum of health professionals. In: Jelliffe DB, Jelliffe EFP, eds. Programmes to Promote Breastfeeding, 1st ed. Delhi: Oxford University Press, 1988; 308-13.

33 Sadeh RJ. Breast Feeding: The Technical Basis and Recommendations for Action. Geneva: WHO, 1993; 63-74.

34 DeChateau P, Wiberg B. Long term effect on mother-infant behavior of extra contact during the first hour postpartum. Acta Paediatr. 1977; 66: 145-51.

35 Taylor PM, Maloni JA, Brown DR. Early suckling and prolonged breast-feeding. Am. J. Dis. Child. 1986; 140: $151-4$.

36 Pérez Escamilla R. Infant feeding policies in maternity wards and their effect on breast-feeding success: an analytical overview. Am. J. Public Health 1994; 84: 8997.

37 Woolridge MW. Problems of establishing lactation. Food Nutr. Bull. 1996; 17: 316-23. 